\title{
Menu-Dependent Emotions and Self-Control
}

\author{
Joaquín Gómez-Miñambres and Eric Schniter*
}

September 25, 2012

\begin{abstract}
We study a dynamic model of self-control where the history of one's decisions (understood as emotions) has influence on subsequent decision making. We propose that effort and regret are emotions produced by previous decisions to either resist or yield to temptation, respectively. When recalled, these emotions affect an individual's preferences, in turn affecting self-control decision at a particular point in time. Our model provides a unified explanation for several empirical regularities puzzling economists and cognitive scientists. We explain non-stationary consumption paths characterized by compensatory indulgence and restraint cycles, why the amplitude of consumption cycles increases with foresight and decreases with emotional memory, and, finally, we show how unavoidable options that might show up on one's menu influence choices, consequent emotions, consumption paths, and preferences for commitment.
\end{abstract}

* Economic Science Institute at Chapman University, One University Drive, Orange, CA, 92866. The paper has benefitted from comments by Robert Kurzban, Gerrit Antonides, Hillard Kaplan, and Stephen Rassenti. We are also grateful to participants of the 6th Annual California Workshop on Evolutionary Perspectives of Human Behavior, the 24th Annual Human Behavior and Evolution Society, the 2012 SABE Workshop for Young Researchers, and the participants of ESI internal seminars for their numerous helpful comments. 
"The only way to get rid of a temptation is to yield to it. Resist it, and your soul grows sick with longing for the things it has forbidden to itself" (Oscar Wilde, The Picture of Dorian Gray, 1891)

"The dieter spots the German chocolate cake on the dessert trolley and is sorely tempted. His rational assessment urges restraint. The weight he will gain, it tells him, is too big a price to pay for the fleeting moment of gastronomic pleasure. Yet, despite this calculation, he often gives in. And when he does, he almost invariably expresses regret." (Robert H. Frank, Passions within Reasons, 1988, p. 86)

\section{Introduction}

Temptation and self-control problems are among the most basic problems that humans struggle with in their moment-to-moment and day-to-day decisions. Many of us repeatedly roller-coaster through regret and effort laden cycles of indulgence and restraint, time and again, sometimes feeling it is impossible to avoid old patterns and to find a stable behavior. Despite the central importance of these fundamental problems, the system producing their dynamics has been poorly understood and remains among the most intriguing puzzles for economist and cognitive scientist to solve (e.g., see Brocas \& Carrillo (2003); Tversky \& Shafir (1992); Pinker (1997)).

The self-control problem presents an apparent paradox: standard economic theories are based on the assumption that consumers choose what they prefer, yet when self-control problems are faced we have evidence that despite stated intentions or preferences people often demonstrate difficulty "committing" to pursuit of those preferences (Strotz (1955)). A popular approach to formalizing this kind of behavior considers individuals' choices to be the products of two utility functions (or goal systems) with conflicting interests. As Schelling (1978) described, sometimes a person "behaves like two people, one who wants clean lungs and long life and another who adores tobacco, or one who wants a lean body and another who wants dessert. The two are in a continual contest for control". 1

\footnotetext{
${ }^{1}$ The internal conflict idea has also been considered and justified in disciplines outside of economics. Evolutionary psychologists (Tooby et al. (2008)) propose adaptive design features of internally conflicted systems (composed of mutually exclusive goal pursuant components) perhaps as adaptive solutions to
} 
An individual characterized as having two utility functions with conflicting goals cannot maximize both preferences at the same time. Therefore, each decision creates unfulfilled preferences or "forgone utilities" -the difference between a maximum possible utility available and a realized utility. The purpose of this paper is to introduce the effects of these forgone utilities (understood as emotions) on future preferences and decisions.

Consider the following example of a consumer who goes daily to the same restaurant for his lunch. The consumer has two conflicting preferences. According to his restraint utility, concerned with long-term health maintenance, the consumer wants to eat a low calorie diet. However, according to his temptation utility, concerned with the immediate satiation of cravings, the consumer wants to eat a relatively high calorie diet. At the restaurant, the consumer considers the possibility of eating cake for dessert. For this example we consider the consumer's set of available alternatives (or menu) to consist of either eating lunch with cake or lunch without cake. On the one hand, if the consumer eats the cake, he is making the best possible decision from the perspective of his temptation preferences while making the worst possible decision from the perspective of his restraint preferences. Thus, when the consumer eats cake, the forgone restraint utility is maximized producing the regret emotion. On the other hand, when the consumer decides not to eat cake the forgone temptation utility is maximized, producing the effort emotion. If the consumer comes back to the restaurant the following day, he may recall his previous selfcontrol decision (to eat or not eat cake) and the emotion produced by it. The recall of the negative emotions effort and regret, produced by previous decisions, causes a devaluation of restraint and temptation utilities, respectively. For instance, recall of regret experienced as a consequence of deciding to eat cake at lunch yesterday makes eating cake at lunch today less desirable. Similarly, the recall of effort experienced as a consequence of deciding not to eat cake yesterday makes eating cake even more desirable today. In other words, the relative weights of conflicting utilities determining a self-control decision at a particular point in time are influenced by recollection of effort and regret generated by previous changing environments (Tooby \& Cosmides (1992)). Moreover, recent developments in neuroscience seem to confirm the idea of a brain composed of conflicting modules. For instance, using brain imaging studies McClure et al. (2004) and Hare et al. (2009) show that two separate neural subsystems are activated when self-control problems are faced and that the relative engagement of one system over the other determines how future utility is traded-off against present utility. Moreover, Livnat \& Pippenger's (2006) analysis of decision making systems finds that under limited computational ability an optimal brain system may involve subsystems that are each in conflict with each other, and despite natural selection acting on whole systems, such internally conflicted systems still manage to evolve. 
decisions. $^{2}$

Temporal inconsistencies in consumption choices, like those described in our cake example, have been established empirically by several experts in management. For instance, Foster et al. (2005) found that when decision makers with conflicting preferences recall past behaviors, they tend to inhibit previously fulfilled preferences and instead activate unfulfilled ones. Based on this idea, Muckopadhyay et al. (2008) found that participants who recalled resisting or yielding to the temptation of eating tasty but unhealthy food demonstrated a "switching pattern": they experienced greater activation of unfulfilled preferences when faced with similar temptations as those faced in the recent past. Thus, as in our cake example, recently indulgent consumers who recall their behaviors tend to show restraint when facing temptations again and recently restrained consumers tend to yield to temptation when recalling their restraint. Similar patterns, like those seen with feasting and fasting behaviors, are often observed among non-pathological (as well as pathological) samples in everyday activities such as shopping, eating, working and moral behaviors. $^{3}$

In the present paper we introduce a self-control model that integrates costs of negative emotions produced by one's previous self-control decisions. Our model provides explanations for the commonly observed non-stationary behavior that individuals demonstrate as they make serial consumption choices according to menu options. In particular, we

\footnotetext{
${ }^{2}$ Our notion of effort as an emotion is illustrated by justifications that consumers frequently invoke for their decisions to indulge. For example, "I deserve to eat cake today because I've behaved so well (having resisted the temptation to eat cake) these past days." Similarly, the notion of regret as an emotion is invoked by justifications for the need to show restraint at future decision junctures. For example, "I don't deserve to eat cake today because I haven't been behaving well (having eaten cake these past days)." This idea of consumers' indulgence as self-reward for prior restraints has also been proposed by Muckopadhyay and Johar (2009).

${ }^{3}$ Impulse-shopping cycles of indulgence and restraint have been observed with student samples by Muckopadhyay and Johar (2009). Describing analyses of data from the Beltsville one year dietary study (Mertz \& Kelsay (1984)), Casper \& Beaton (1992) describe "normal" day-to-day cycles of caloric consumption cycling between positive and negative energy balance among non-bulimic samples. Pathological consumption patterns (e.g., anorexia and bulimia) that also cycle between periods of bingeing and compensatory fasting (Kurth et al. (1995); Heatherton et al. (1995)) are well documented by psychiatric and health-care professionals who also note that these consumption patterns are closely related with and regulated by negative emotional experiences. In particular, as a consequence of these extreme consumption behaviors, individuals report high negative affect after bingeing and purging (Lynch et al. (2000)) that could become pathological (bulimia nervosa) when individuals fail to regulate them (Whiteside et al. (2006)).
} 
consider that previous forgone utilities (experienced as emotions) could affect present decisions through their impact on preferences. Let $M$ denote the menu of alternatives available for consumption, $U$ denotes the restraint utility and $V$ denotes the temptation utility. If we call $e_{t}$ the history of forgone temptation utilities (effort) and $g_{t}$ the history of forgone restraint utilities (regret), the individual's (overall) utility in period $t$ is given by

$$
W_{t}(M)=\max _{x \in M}\left[U\left(x, e_{t}\right)+V\left(x, g_{t}\right)+\delta W_{t+1}\right]
$$

where $\delta \in[0,1]$ is the consumer's discount factor.

In our setting, forgone utilities (captured by $e_{t}$ and $g_{t}$ ) affect the balance of power between the individual's preferences and hence they will have an impact on individual's decisions. In other words, restraint and temptation preferences (i.e., long-sighted and short sighted goals) are defined by not only current actions but also the stocks of forgone utilities produced by previous self-control decisions (represented emotionally). We interpret $e_{t}$ as an effort-like emotion that is experienced as a consequence of resisting temptation (and forgoing the short-sighted goal of indulging temptation) and $g_{t}$ as a regret-like emotion that is experienced as a consequence of yielding to temptation (and forgoing the long-sighted goal of exercising restraint). Both emotions are negative in the sense that they impose costs, decreasing the cardinal scale of the targeted utilities. Effort targets $U$ imposing cost to down-regulate its relative power while regret targets $V$ imposing cost to down-regulate its relative power over the consumption decision.

To facilitate the analysis and interpretation of our model we use a Hotelling specification, derived from Hotelling's (1929) location model, where mutually exclusive and conflicting preferences are located at the extremes of a unit length segment. This "Hotelling line" provides an intuitive way to capture differences in restraint and temptation preferences as different "ideal points" in a characteristic space. We can generalize our introductory cake example by considering that different points on the Hotelling line would represent different kinds of cakes, situated according to their caloric value. Higher calorie cakes would be located closer to temptation preferences while lower calorie cakes would be located closer to restraint preferences. A menu, representing the alternatives faced by an individual, contains a subset of all possible cakes included on the Hotelling line. Therefore, under this specification, forgone utilities (and their corresponding negative emotions) are proportional to Euclidean distances between the point of an actual consumption alterna- 
tive (i.e., the chosen cake) and the boundaries of the menu. If the individual has taken actions closer to the ideal point of restraint (e.g., by consuming low calorie "diet" cakes instead of available high calorie cakes), the "effort" experienced from resisting temptation will be higher, in turn decreasing the relative weight of the restraint preference (and thus the appeal of the "diet" cake over the "real thing"). Thus, future attempts to resist available high calorie temptations, even with the aid of available diet cakes, will be more difficult. Similarly, if an individual has been taking actions closer to the ideal temptation point (i.e., by consuming high calorie cakes), the regret experienced as a consequence of yielding to temptation will be higher, in turn decreasing the relative cardinal scale of temptation preference. Thus, future attempts to resist temptation will be easier.

Several results of our model provide evidence of non-stationary self-control behaviors. First, we consider a model with a given menu that is known by the consumer. We show that the optimal consumption path follows compensatory feasting and fasting cycles and that there is a last period craving effect - the shape and amplitude of which depend on the given menu $(M)$, the consumer's discount factor $(\delta)$, and the degree to which emotions are recalled (i.e., the emotional memory). Second, we consider a model where, the consumer initially commits to a menu that he will face in subsequent consumption periods unless uncontrolled alternatives arise (which we examine the consequences of). Coming back to our restaurant and cake example, we illustrate how an uncontrolled alternative might arise despite a consumer's attempts to face a regular menu: the consumer who visits the same restaurant daily could be faced with a new "special" being offered: a new kind of German chocolate cake with even higher caloric value than the one normally available. Alternatively, we can interpret this model by considering the example of a consumer who shops for her week's meals at the beginning of the week (a commitment menu) but later encounters unexpected alternatives (e.g. free food samples, snacks shared by a coworker, friends' invitations to eat out, etc.) affecting her set of available alternatives for consumption. The new alternatives, even if they are not chosen, generate menudependent emotions that affect subsequent preferences and decisions. Thus, the special German chocolate cake could trigger consumption of cakes that otherwise would have no been made. As we show, our model predicts that forward-looking consumers will demand commitment menus with some (but not full) flexibility. While small (full-commitment) menus minimize the emotions generated when no uncontrolled alternatives arise, with flexible menus, consumers are better able to adapt their consumption to the emotional effects produced by uncontrolled alternatives when they appear. 


\section{Literature Review}

There are at least two important economic literatures that are related to our work: one on addiction and another on temptation and self-control. In the psychology literature our paper is related to works about ego-depletion and self-control as a limited resource.

The addiction literature most relevant to our paper involves models that account for an extended utility function (Becker (1996)). These addiction models provide a function, not only defined by present consumption trade-offs, but also "extended" to include a stock of past consumption, called "consumption capital". The important feature of this class of models is that, while preferences remain stable, they are defined by not only "ordinary goods" but also by features (e.g., past consumption, social desirability, or emotions) not normally thought of as "goods". For instance, Stigler and Becker (1977) introduce a model of "rational addition", extended further by Iannaccone (1986), where present marginal utility increases with consumption capital. Becker and Murphy (1988) develop much more this theory introducing intertemporal decision making. Laibson (2001) and Bernheim and Rangel (2004) extend this rational addiction idea to include the effects of environmental cues which trigger consumption of an addictive good. Our self-control model shares some features in common with the addiction literature: it is also based on the idea of extended utility function, although our analysis relapses on forgone utilities from past consumption decisions and hence on emotional capitals, and it also considers the effects of environmental cues, which in our model are the restraint and temptations options provided by menus.

In a note elaborating on Becker and Murphy (1988), Dockner and Feichtinger (1993) show cyclical consumption introducing two consumption capitals (eating capital and weight capital) in an extended utility function. Although related, our extended utility analysis includes several novelties with important implications. First, in considering an individual's two internally-conflicted preferences we specify not one but two different extended utilities. More importantly, in determining the marginal utility of consumption we model emotional capital as captured by stocks of previous forgone utilities (and their emotional consequences), not just a single stock of previous consumption. Since forgone utilities depend upon options not chosen, the menu's set of alternatives (specifically, the available options) plays a very important role in determining our extended utilities, while it would be irrelevant under the concept of consumption capital in models of addiction. Finally, our concept of negative emotions departs from models of addiction because the emotionally regulated consumption in our model presents "adjacent substitutabil- 
ity" across periods. Thus, in contrast to the standard consumption capital in models of addiction, the marginal utilities in our model decrease with the experience of negative emotions.

Gul and Pesendorfer (2001) provide a popular representation of temptation and selfcontrol that uses a dual-utility model to capture the idea that self-control can be costly and incomplete. In their model the forgone temptation utility derived from a decision is a linear self-control cost that favors the choice of small menus (a preference for commitment). However, consumption choices made from menus are unaffected by previous self-control costs. Therefore, their model cannot explain the non-stationary behavior that is so commonly found among those struggling with self-control problems.

There are several extensions of Gul and Pesendorfer (2001). Kopylov (2012) and Sarver's (2008) include forgone restraint utility, i.e., regret. Unlike our model where regret also affects choices from menus, in these papers regret only affects choices of menus (but not choices from menus). Some authors have criticized Gul and Pesendorfer's (2001) idea of linear self-control costs and its implications for menu preferences. Dekel et al. (2009) provide a contrasting view to the assumption that only the most tempting offer determines self-control costs. In the Dekel et al. (2009) representation, self-control costs can be affected by several options on the menu. Fudenberg and Levine (2006, 2010) consider a version of the Gul and Pesendorfer (2001) representation where the self-control cost is nonlinear. In these models more numerous temptations are more difficult to resist because of cognitive load that is thought to increase with each additional temptation. Noor and Takeoka (2011) consider yet another extension of Gul and Pesendorfer (2001)'s representation where cost of self-control is the forgone temptation utility scaled up by the "degree of temptation" as represented by the most tempting offer on the menu. Therefore, as in our model, Noor and Takeoka (2011) also consider a model with menu-dependent self-control. However, in contrast with their paper, we consider a self-control model where the menus not only affect temptation but also restraint. Moreover, in our representation self-control is affected by previous forgone utilities (emotions); not only affecting choices of menus but also choices from menus.

A few papers have introduced time in a self-control model. Gul and Pesendorfer (2004) provide axioms for a recursive self-control model where, each period, an individual makes a consumption decision and chooses a menu for the next period. Using this recursive self-control idea, Gul and Pesendorfer (2007) study addiction in a self-control model with conflicting utilities. Addiction is introduced in the model because previous consumption 
determines the marginal temptation utility in the next period. The authors apply the model to explain the case where an addict who faces a constant drug menu over time and consumes drugs can also decide to enter a rehabilitation center where drug consumption is forced to zero. The authors show that, in equilibrium, the consumer increases drug consumption until deciding to enter rehab. Explained in terms of internal conflict: as drug consumption increases, the relative power of the tempted utility decreases until the restraint utility has relatively dominant power: leading the addict to check into rehab and remain until released, at which point the addiction/rehab process restarts. To our knowledge, Gul and Pesendorfer (2007) is the only paper that incorporates the idea of addiction, and hence nonstationary behavior, in a dual-utility self-control model, making it the paper most closely related to our work. However, our analysis has many important differences. First, in our model consumption today depends on consumption history, not only on the last period. More importantly, we consider emotional capital (i.e., history of forgone utilities) instead of consumption capital. Thus, when faced with a consumption decision, one's state (which affects self-control) not only depends on previous consumption but also on the set of available alternatives. As we shall see, internal calibration of the conflicting preferences is managed by the emotions of regret and effort (consequences of previous forgone restraint and forgone temptation utilities, respectively). Finally, one of our model's novel contributions derives from its ability to consider potential effects of uncontrolled options appearing on menus, which can have a disruptive effect on an individual's state. An important result derived from consideration of these hazards is that rational individuals commit to flexible (not highly constrained) menus allowing them to adapt consumption to changes in emotional states created by the uncontrolled options that can arise in the menu

Our paper is also related to the psychology literature on "ego-depletion" that considers individuals' self-control or will-power as a limited resource (Baumeister et al. (1998)). The ego-depletion theory proposes that self-control involves the expenditure of some kind of energy (e.g. as might be provided by glucose reserves) that becomes depleted when a restraint decision is made. Ego-depletion theory argues that, with a depleted reserve an individual faces greater difficulty resisting temptation. Recently, the theory has been criticized by several authors that do not find support for various limited-reserve depletion hypotheses, including those based on glucose depletion (Kurzban (2010), Job et al. (2010)). Similarly, our model does not assume that self-control is a limited resource but considers that self-control decisions are costly, taking the form of emotional costs, and 
that these costs are determined by past forgone utilities. Therefore, to explain the cyclical consumption pattern of consumers struggling with self-control problems, we do not need to assume that self-control is a limited resource but rather that resisting or succumbing to temptation is costly and that the costs increase positively with previous forgone temptation or restraint utilities, respectively. An advantage of our concept of emotions affecting the relative cardinal scales of conflicting utilities is that it provides an alternative explanation for why an individual might switch from resisting to yielding to temptation without invoking the controversial idea of self-control as a limited resource.

The paper proceeds as follows. Section 2 describes the setup of the model. In Section 3 we consider two important benchmarks: the fully myopic model and the two period model. In Section 4 we present results of the general model. Section 5 discusses the implications of menu uncertainty and preferences for commitment, and Section 6 concludes with discussion.

\section{The Model}

We consider an individual deciding on actions over several periods of time. Time is discrete and indexed by $t=1,2, \ldots, T$, where $T<\infty$. Individual's actions are represented as locations on a Hotelling line of unit length $[0,1]$. We denote by $x_{t}$ the individual's action (or consumption choice) in period $t$ and define $M$ as the time invariant compact set of available alternatives (or menu). ${ }^{4}$ The menu is a closed interval that lies on the Hotelling line. Thus, $M \equiv[\underline{m}, \bar{m}] \subseteq[0,1]$ with $\underline{m} \leq \bar{m}$. We assume that the individual is perfectly informed about the alternatives on the menu.

Consistent with dual-preferences models in behavioral economics and psychology we assume that the individual is characterized by two different utilities. We denote these utility functions by $u$, the restraint utility, and $v$, the temptation utility. We assume that preferences are located at the extremes of the Hotelling line. Without loss of generality we consider that the restraint ideal point is located at zero while the temptation ideal point is located at one. Therefore, the individual utilities are given by:

$$
\begin{aligned}
& u\left(x_{t}\right)=s-t\left(x_{t}, 0\right), \\
& v\left(x_{t}\right)=s-t\left(x_{t}, 1\right) .
\end{aligned}
$$

\footnotetext{
${ }^{4}$ In Section 5 we will also consider the case of a time-variant set of alternatives.
} 
where $s \in \mathbb{R}_{+}$represents the maximum surplus and $t(x, \theta)=(\theta-x)^{2}$ with $\theta \in\{0,1\}$ represents the transportation costs (i.e., the disutility experienced by the consumer when his consumption, $x$, is different from his ideal point, $\theta$ ).

As discussed in the introduction, when an individual with mutually exclusive dualpreferences makes a decision, he cannot maximize both utilities simultaneously. Given the individual action $x_{t}$ in period $t$, the forgone utilities of competing preferences $u$ and $v$ are $i^{u}=\max _{x \in M} u(x)-u\left(x_{t}\right)$ and $i^{v}=\max _{x \in M} v(x)-v\left(x_{t}\right)$ respectively. Note that resisting temptation (i.e., $x_{t}$ close to zero) creates a high forgone $v$-utility (but a low forgone $u$-utility), while yielding to temptation (i.e. $x_{t}$ close to one) generates a high forgone $u$-utility (but a low forgone $v$-utility). By simplicity of exposition sometimes we will refer to $x_{t}$ closer to 1 or closer to 0 as higher or lower consumption. We define emotional capital as the sum of all previous forgone utilities depreciated at a constant rate. In particular, the effort capital transition equation is given by

$$
e_{t+1}=(1-\lambda) e_{t}+\left[\max _{x \in M} v(x)-v\left(x_{t}\right)\right],
$$

while the regret capital transition equation is

$$
g_{t+1}=(1-\lambda) g_{t}+\left[\max _{x \in M} u(x)-u\left(x_{t}\right)\right] \text {. }
$$

Where initial conditions $e_{1}=g_{1}=0$, and $\lambda \in[0,1]$ represents the psychological depreciation rate of emotions. We refer to $(1-\lambda)$ as emotional memory. In this sense, when an emotion is "remembered" it imposes cost on a targeted self-control utility. Emotions that have fully depreciated cannot be remembered, or impose costs. Thus, under this interpretation, emotional capitals are the remembered forgone utilities at a particular point in time while forgone utilities, $i^{u}$ and $i^{v}$, produce new emotions every period. Moreover, we define an individual's emotional balance as the difference between both kinds of emotional capital:

$$
B_{t+1}=e_{t+1}-g_{t+1}=(1-\lambda) B_{t}+1-2 x_{t}+\mu(M)
$$

where $\mu(M)=\underline{m}^{2}-(1-\bar{m})^{2} \in[-1,1]$ is a function that depends on boundaries of the menu. This function indicates that emotions depend, not only on previous actions, but also on available menu options. If $\mu(M)>0$ the menu contains more alternatives closer to the temptation preference, we say that the menu is temptation shifted. Similarly, if $\mu(M)<0$ the menu contains more alternatives closer to restraint preference, we say that the menus is restraint shifted. Finally, if $\mu(M)=0$ the menu does not favor one kind of 
preferences over the other, we say that the menu is neutral. By notational convenience we will sometimes refer to this function just as $\mu$.

Now we can define the following extended utility functions in period $t$ that depend on the actual action (the state variable) and the emotional capital (the control variable) at each period:

$$
\begin{aligned}
U\left(x_{t}, e_{t}\right) & =u\left(x_{t}\right)-\rho \varepsilon\left(x_{t}, e_{t}\right), \\
V\left(x_{t}, g_{t}\right) & =v\left(x_{t}\right)-\rho \gamma\left(x_{t}, g_{t}\right) .
\end{aligned}
$$

Where $\rho \in \mathbb{R}_{+}$and $\varepsilon\left(x_{t}, e_{t}\right)$ and $\gamma\left(x_{t}, g_{t}\right)$ are emotional cost functions. In particular, we consider that $\varepsilon\left(x_{t}, e_{t}\right)=e_{t}\left(1-x_{t}\right)$ and $\gamma\left(x_{t}, g_{t}\right)=g_{t} x_{t}$. These functions capture the idea that decisions can be emotionally costly. The closer $x_{t}$ is to the temptation ideal point, $\theta=0$, the higher the individual's emotional cost of effort. While the closer $x_{t}$ is to the restraint ideal point, $\theta=1$, the higher the individual's emotional cost of regret. The linearity of the functions assures that the marginal costs of the individual's decision are given by the emotional capitals. Thus, to yield to temptation is costly (taking the form of regret costs) and it is even more costly if the individual has previously yielded to temptation, and hence accumulated regret capital. Similarly, resisting temptation is costly (taking the form of effort cost) and more costly if the individual has previously resisted temptation, and hence accumulated effort capital. ${ }^{5}$

Note that, while the primitive utility functions, $u$ and $v$, are constant, the extended utilities that incorporate emotional capital depend on $t$ and are therefore non-stationary.

We introduce an emotional self-control representation that incorporates our notion of costly emotions.

$$
W_{t}(M)=\max _{x \in M}\left[U\left(x, e_{t}\right)+V\left(x, g_{t}\right)+\delta W_{t+1}\right] .
$$

Where $\delta \in[0,1]$ is the individual's discount factor. Note that if $\rho=0$, we have a standard model with no history effects where individual preferences are $W\left(x_{t}\right)=u\left(x_{t}\right)+v\left(x_{t}\right)$. However, the key point of our representation arises when $\rho>0$, that is, when emotional capitals affect the relative cardinal scale of the extended utilities. In this case previous decisions to resist or yield to temptation affect present decisions through emotional costs.

The action at period $t$ will depend on the current emotions, $x_{t}=\alpha_{t}\left(e_{t}, g_{t}\right)$ where $\alpha_{t}$ is referred to as the decision rule. An optimal decision rule solves the following maximization

\footnotetext{
${ }^{5}$ Alternatively, we can interpret these functions as "transportation costs" that act in the opposite direction of the standard transportation costs and whose magnitude increase with emotional capital (i.e., with previous self-control decisions).
} 
problem every period:

$$
W_{t}(M)=\max _{x \in M} U\left(x, e_{t}\right)+V\left(x, g_{t}\right)+\delta W_{t+1} .
$$

Where $e_{t}$ and $g_{t}$ evolve according to the transition equations previously described. A decision (consumption) path is a sequence of decision rules $\left(\alpha_{0}, \alpha_{1}, \ldots, \alpha_{T}\right)$. We say that a decision path is stationary if decision rules do not depend upon time $\alpha_{t}(e, g) \equiv \alpha(e, g)$.

Note that, in contrast to a standard utility model $(\rho=0)$ and self-control models with linear self-control costs (Gul and Pesendorfer (2001) or Kopylov (2012)), our representation implies a violation of the Weak Axiom of Revealed Preferences. To see this, let's consider $M=\left[0, \frac{1}{2}\right]$ and an individual with $\rho>0$ and who does no discount the future (i.e., $\delta=0)$. Since the individual starts with no emotions (i.e., $U\left(x_{1}, e_{1}\right)=u\left(x_{1}\right)$; $\left.V\left(x_{1}, g_{1}\right)=v\left(x_{1}\right)\right)$, the action taken in the first period is $x_{1}=\underset{x \in\left[0, \frac{1}{2}\right]}{\arg \max } u\left(x_{1}\right)+v\left(x_{1}\right)=\frac{1}{2}$.

Therefore, the effort capital in period 2 will be zero while the regret capital will be $\frac{1}{4}$. This leads to the following extended preferences in period 2 :

$$
\begin{aligned}
U\left(x_{2}, e_{2}\right) & =u\left(x_{2}\right) \text { and } \\
V\left(x_{2}, g_{2}\right) & =v\left(x_{2}\right)-\rho \frac{1}{4} x_{2} .
\end{aligned}
$$

Therefore, the action in period 2 will be $x_{2}=\underset{x \in\left[0, \frac{1}{2}\right]}{\arg \max } U\left(x, e_{2}\right)+V\left(x, g_{2}\right)=\frac{1}{2}-\frac{\rho}{16}<\frac{1}{2}$. Thus, although the individual reveals a preference for $\frac{1}{2}$ over $\frac{1}{2}-\frac{\rho}{16}$ in period 1 , he reveals the opposite in period 2. This is not the case when emotions plays no role $(\rho=0)$. In contrast with a standard self-control representation, decision paths can be non-stationary in our model.

Although in this paper we mainly focus on choices from menus, and the implications for non-stationary behavior, we also consider choices of menus in Section 5.

\section{Benchmarks}

In this section we study two benchmark specifications that are particular cases of our model. First we study the case in which the individual has only preferences for the present. Second, we study the case with two periods. 


\subsection{The Fully Myopic Model}

We find it useful to start our model analysis by considering the benchmark produced by a fully myopic individual: one who has no future thought and only preferences for the present $(\delta=0)$. This consumer's actions only take into account his present emotional capital, not how his decisions affect future emotional capital and hence future extended utilities and decisions. In this case, consumption decisions maximizes the sum of the two competing extended utilities $U\left(x, e_{t}\right)+V\left(x, g_{t}\right)$ every period. Therefore, $x_{t}=\frac{1}{2}+\frac{\rho}{4} B_{t}$. Hence, the consumer's action is closer to the restraint preference if the emotional balance is negative $\left(e_{t}<g_{t}\right)$ and closer to the temptation preferences if the emotional balance is positive $\left(e_{t}>g_{t}\right)$.

The next lemma summarizes the result of the myopic benchmark.

Lemma 1 If the individual is myopic $(\delta=0)$ his consumption in period $t \in\{1,2, \ldots, T\}$ is

$$
x_{t}=\frac{1}{2}+\frac{\rho}{4} B_{t}
$$

with $B_{t}=2 \mu \frac{1-\left[1-\lambda-\frac{\rho}{2}\right]^{t-1}}{2 \lambda+\rho}$.

In the following corollary we show under which circumstances the consumption path tends to a stable steady state.

Corollary 1 If the individual is myopic $(\delta=0)$ and $\rho+2 \lambda<4$ then there exists a stable steady state given by

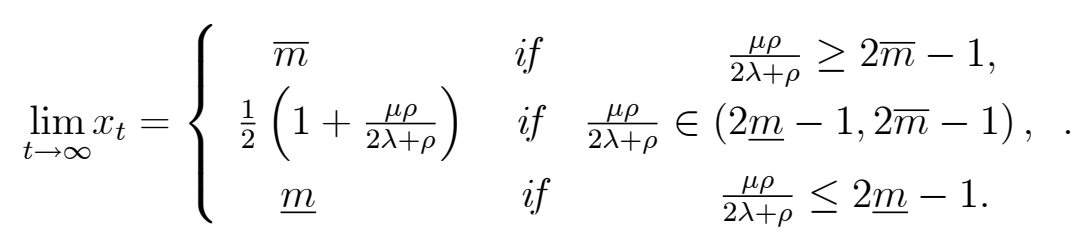

Graphically, 


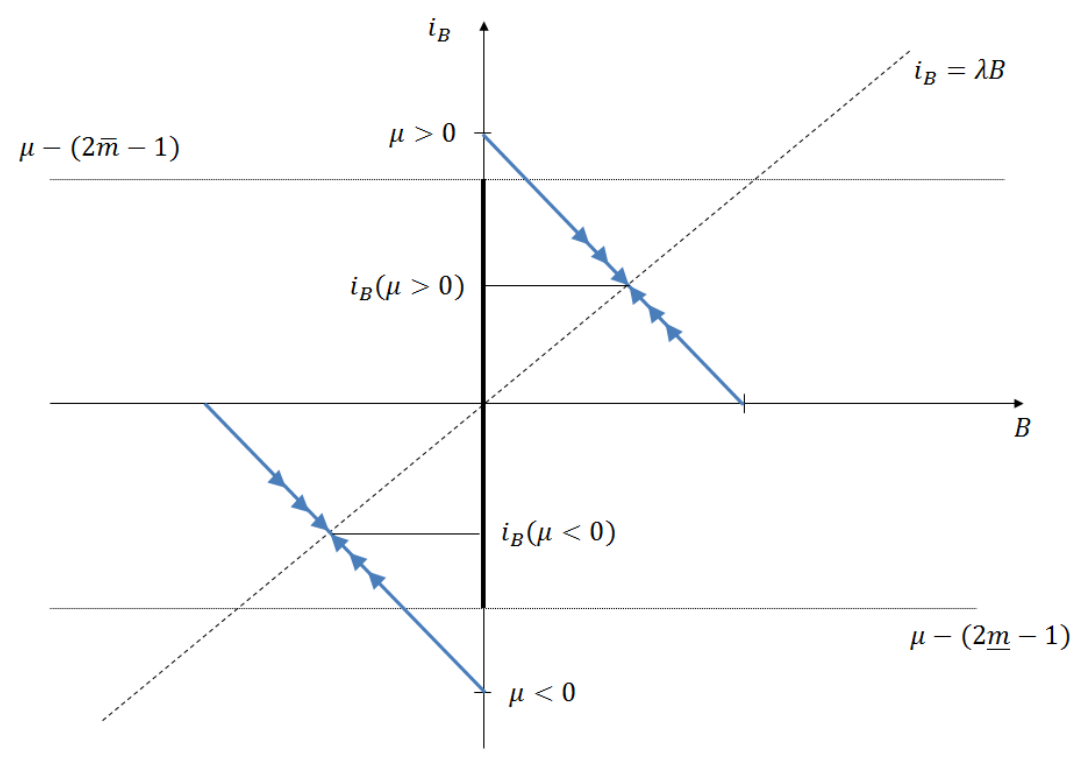

Figure 3.1. The steady state in the fully myopic benchmark.

The horizontal axis in Figure 2.1 graphs the emotional balance, while the vertical axis graphs investments in emotional balance. Thus, $i_{B}=\left[\max _{x \in M} v(x)-v\left(x_{t}\right)\right]-$ $\left[\max _{x \in M} u(x)-u\left(x_{t}\right)\right]=1-2 x_{t}+\mu$. The blue lines represent the amount an individual invests in emotional balance as a function of the emotional balance $\left(i_{B}=\mu-\frac{\rho}{2} B\right)$, the vertical lines $\mu-(2 \underline{m}-1)$ and $\mu-(2 \bar{m}-1)$ represent the bounds of the menu. If $\mu>0$, an interior steady state has a positive emotional balance (effort greater than regret) while if $\mu<0$, the emotional balance will be negative (regret greater than effort).

By Corollary 1 we know that a fully myopic individual's action tends to a stable steady state when emotions have a small impact on the individual's preferences ( $\rho$ is low) or when the individual remembers most of the previous emotions ( $\lambda$ is low). Note that, although equivalent in the individuals actions, both cases have different implications for individual's payoffs. In the first case, the individual just doesn't tend to recall negative emotions, so regret and effort don't impose significant costs and don't have a big impact on decisions. However, in the second case the individual's recall of past emotions, although costly, calibrate consumption and achieve consistent behavior.

In the following corollary we summarize the menu effect on the consumption path.

Corollary 2 If the individual is myopic $(\delta=0)$, then $\frac{d\left|x_{t+1}-x_{t}\right|}{d|\mu|}>0$.

Therefore, the amplitude of the consumption cycles increases with shift of the menu $|\mu|$. Since the individual starts emotionally balanced, we know by Lemma 1 that $x_{1}=\frac{1}{2}$. 
Therefore, a greater asymmetry (or shift) of the menu with respect to $\frac{1}{2}$ corresponds to greater forgone utilities created by the consumption decision $x_{1}$. If the menu is temptation shifted $(\mu>0)$, the forgone temptation utility will be high. If the menu is restraint shifted $(\mu<0)$, the forgone restraint utility will be high. In both cases the absolute value of emotional balance in the next period $\left(\left|B_{2}\right|\right)$ will be high and, therefore, the difference between consumption actions across periods $\left(\left|x_{2}-x_{1}\right|\right)$ will be high as well.

In figure 2.2 we plot the decision path of the myopic individual with a temptation shifted menu.

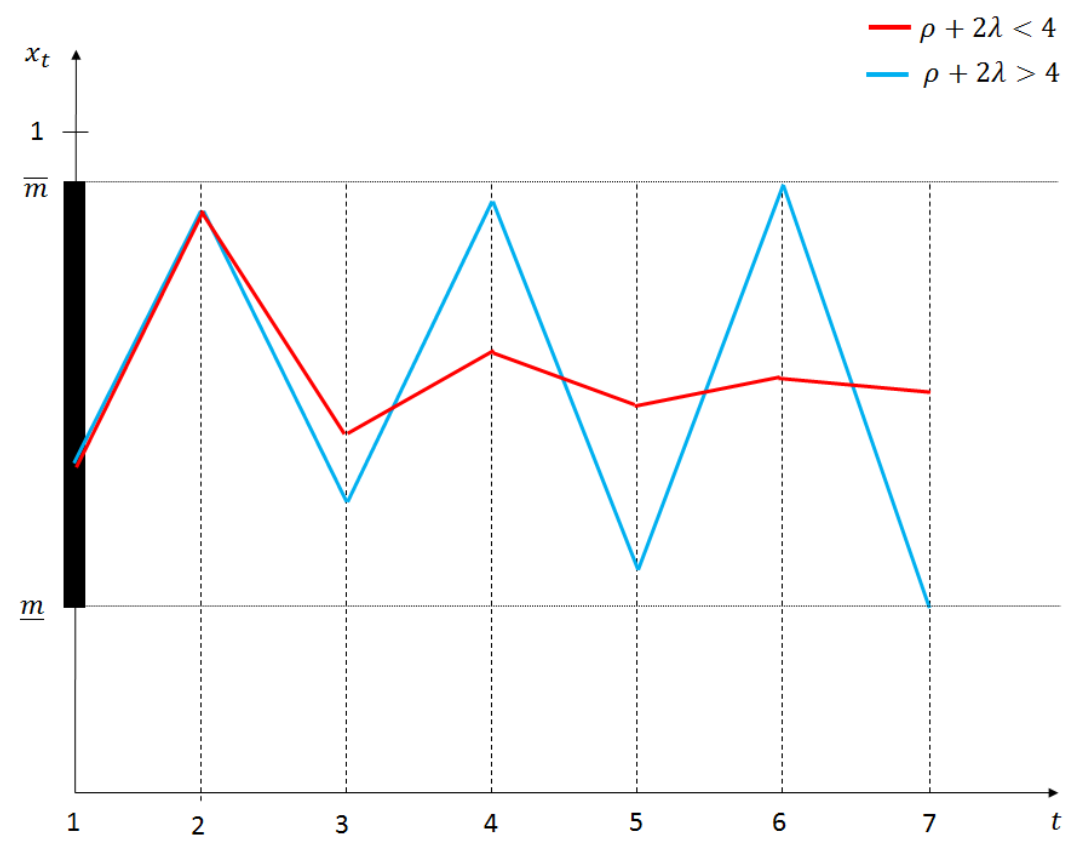

Figure 3.2. Decision paths in the fully myopic benchmark: stability and instability.

Note that the decision path follows compensatory feasting and fasting cycles where the individual alternates between periods of yielding to temptation, and hence high regret, with periods of resisting temptation, and hence high effort. If the impact of emotions $(\rho)$ and the depreciation rate $(\lambda)$ are sufficiently high, this behavior persists indefinitely. Otherwise, the amplitude of consumption cycles decreases over time and consumption tends to a stable steady state. 


\subsection{The Two Period Model}

We begin our analysis of consumption decisions in which a consumer anticipates the future $(\delta>0)$ by considering a two period model $t \in\{1,2\}$. Note that since we assume that the individual starts in a state of emotional balance $\left(B_{1}=0\right)$, the emotional memory $(\lambda)$ has no impact in this model because there are no first period emotions to recall in the second period. Only second period emotions created as a consequence of first period decision will determine the emotional balance in the second period. While we analyze the model for an arbitrary number of periods in the next section, we use a simplified version of the model with two periods below to obtain a closed form solution that facilitates conceptual understanding of the model.

We solve the model by backward induction. Given period 1 action $\left(x_{1}\right)$, which generates emotions $\left(e_{2}=\max _{x \in M} v(x)-v\left(x_{1}\right)\right.$ and $\left.g_{2}=\max _{x \in M} u(x)-u\left(x_{1}\right)\right)$, the emotional balance in period 2 is given by $B_{2}=e_{2}-g_{2}=1-2 x_{1}+\mu$. Therefore we can get second period consumption by solving the following maximization problem:

$$
x_{2} \in \underset{x \in M}{\arg \max } U\left(x, e_{2}\right)+V\left(x, g_{2}\right)
$$

whose solution is

$$
x_{2}=\frac{1}{2}+\frac{\rho}{4} B_{2}
$$

Given the solution for the second period, we can then calculate first period consumption as the solution to the following maximization problem:

$$
x_{1} \in \underset{x \in M}{\arg \max } U(x, 0)+V(x, 0)+\delta W_{2}
$$

where

$$
W_{2}=U\left(x_{2}, e_{2}\right)+V\left(x_{2}, e_{2}\right)
$$

whose solution is ${ }^{6}$

$$
x_{1}=\frac{1}{2}-\frac{\delta \rho^{2}}{8+4 \delta \rho\left(1-\frac{\rho}{2}\right)} \mu
$$

Hence, by substituting (2) in (1) we get the solution of consumption in the second period

$$
x_{2}=\frac{1}{2}+\frac{\rho(2+\delta \rho)}{8+4 \delta \rho\left(1-\frac{\rho}{2}\right)} \mu
$$

\footnotetext{
${ }^{6}$ Second order condition: $-4-2 \delta \rho+\delta \rho^{2}<0$ is satisfied for any $\rho<1+\sqrt{5} \simeq 3.24$. In the next section we show that the second order condition is satisfied for an arbitrary number of periods, when $\rho<2$.
} 
Note that if $\rho=0$ (emotions play no role) or the menu is neutral $(\mu=0)$, we get stationary consumption $\left(x_{1}=x_{2}\right)$. However, when the menu is shifted $(\mu \neq 0)$ and emotions affect the individual's payoff $(\rho>0)$, the path of consumption choices over time can be very different. In the next proposition we summarize the results of the two period model.

Proposition 1 In the two period model, if $\delta>0, \rho>0$ and $|\mu|>0$, we have:

(i) $x_{1}<\frac{1}{2}<x_{2}\left(x_{1}>\frac{1}{2}>x_{2}\right)$ iff $\mu>0(<0)$.

(ii) $\frac{d\left|x_{2}-x_{1}\right|}{d \delta}>0$.

(iii) $\frac{d\left(x_{2}+x_{1}\right)}{d \delta}<0(>0)$ iff $\mu>0(<0)$.

(iv) $\frac{d\left|x_{2}-x_{1}\right|}{d \rho}>0$.

(v) $\frac{d\left(x_{2}+x_{1}\right)}{d \rho}>0(<0)$ iff $\mu>0(<0)$.

In our model, identical consumption can produce different emotional consequences when individuals are exposed to different menus. For example, consumption would produce higher effort than guilt when the menu is temptation shifted, while higher guilt than effort would be produced by identical consumption from a restraint shifted menu. Since the balance of emotions produced are different as a consequence of available menu options, extended preferences, and hence decisions, are different under different menus. A forward-looking individual will anticipate emotional consequences and therefore make consumption decisions based on expected emotional consequences. Proposition 1 concerns the consequences of this future anticipation. The first part of the proposition states that the optimal consumption path is characterized by opposing self-control decisions in adjacent periods. For example, resisting temptation in the first period and yielding to temptation in the second period. If a forward-looking consumer faces a menu that makes resisting temptation more difficult (i.e., the menu is temptation shifted), high consumption will be anticipated for the second period. With higher consumption anticipated in the second period, the marginal costs of guilt gain importance in determining the individual's extended preferences. Since the marginal guilt cost is generated as a consequence of first period decision, a forward-looking individual wants to lower guilt by decreasing first period consumption. Similarly, if a consumer faces a menu that favors low consumption (i.e., the menu is restraint shifted) he anticipates low consumption in the second period. Low second period consumption implies that effort costs produced by first period consumption have a greater impact on the individual's extended preferences. Therefore, a 
forward-looking individual wants to keep effort low by increasing first period consumption. By $(i i)$ we know that the difference in the consumption between both periods increases with the discount factor. That is, the individual with a high discount factor is more willing to sacrifice first period welfare, controlling his emotions to increase second period benefits. In ( iii) we show that when the menu is either temptation or restraint shifted, the sum of first and second period consumption decreases or increases, respectively, with the discount factor. Therefore, total consumption is less influenced by the menu when a consumer is forward-looking. In other words, the inconsistency in consumption choices generated by a forward-looking individual serves to minimize the negative consequences of shifted menus on welfare. Parts $(i v)$ and $(v)$ in Proposition 1 provide comparative statics for the impact of the emotions parameter $(\rho)$. It is not surprising that, as shown in $(i v)$, emotions with greater impact generate a higher consumption inconsistency since, as we have explained, this is the strategy that forward-looking individuals use to minimize the negative consequences of emotions on the their payoffs. Moreover with $(v)$ we verify that greater impact of emotions increases the consumption response to menu's shift. If the menu is either temptation or restraint shifted, total consumption is higher or lower, respectively, in relation to the degree of impact that emotions have on an individual's payoff.

\section{The Optimal Consumption Path}

In this section we analyze the optimal consumption path for any $\delta \in[0,1]$ and $T<\infty$. We relegate all the technical details to the appendix and present here a comparative statics analysis based on simulations. ${ }^{7}$

As we argued in the last section, emotions can create a non-stationary consumption path. In Section 3.1 we checked that when the individual is myopic, he alternates between periods of high consumption, and hence high regret, with periods of low consumption, and hence high effort (Lemma 1). We also checked that consumption cycles tend to a steady state when the impact of emotions $(\rho)$ and/or the depreciation rate $(\delta)$ are sufficiently high, but increase in amplitude over time otherwise (Corollary 1). Moreover, we checked that the amplitude of these cycles increases with the shift of the menu $(|\mu|)$ (Corollary 2). In Section 3.2 we solve the case of a forward-looking individual with only two periods. We

\footnotetext{
${ }^{7}$ Simulations are done using Matlab 7 software. Matlab codes are available upon request.
} 
checked that the amplitude of the cycles not only increases with the shift of the menu, but also with the discount factor $\delta$ (Proposition 1). Now we will check whether the optimal consumption path is also affected by menu-dependent emotions in the general model.

In Figure 4.1. we can observe the effects of emotions on the consumption path when the menu is temptation shifted $(\mu>0)$. In red we have a model where emotions play no role $(\rho=0)$ and in blue we have the case with emotions $(\rho>0)$. As we can see, emotions create a non-stationary consumption path.

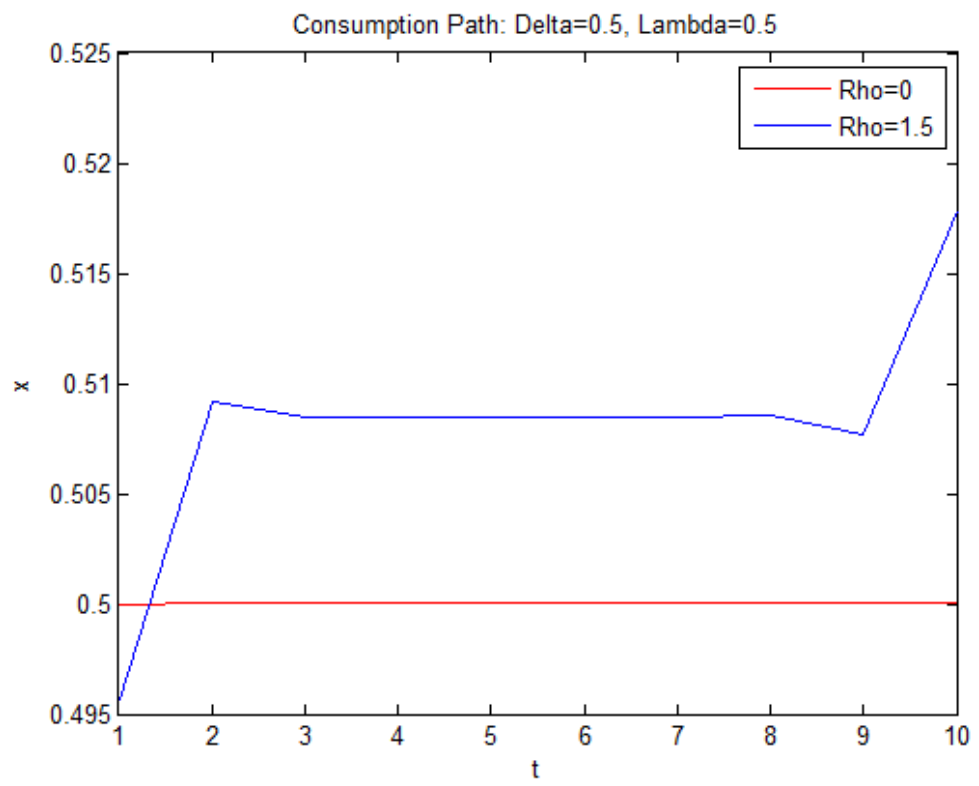

Fig. 4.1. Non-stationary consumption path.

This path is affected by the menu. When the menu is temptation shifted there are relatively more tempting options to resist. Thus, the effort emotion has a comparatively larger effect, in turn favoring the relative power of the temptation preference such that consumption will tend to be closer to one. As we observe (see Figure 4.2.), if the menu is restraint shifted $(\mu<0)$ we have the symmetric effect. Under restraint shifted conditions the menu favors regret, which increases the bargaining power of the restraint preference, so consumption tends to be closer to zero. Whereas, if the menu is neutral $(\mu=0)$, both emotions are equally important and consumption is stationary. 


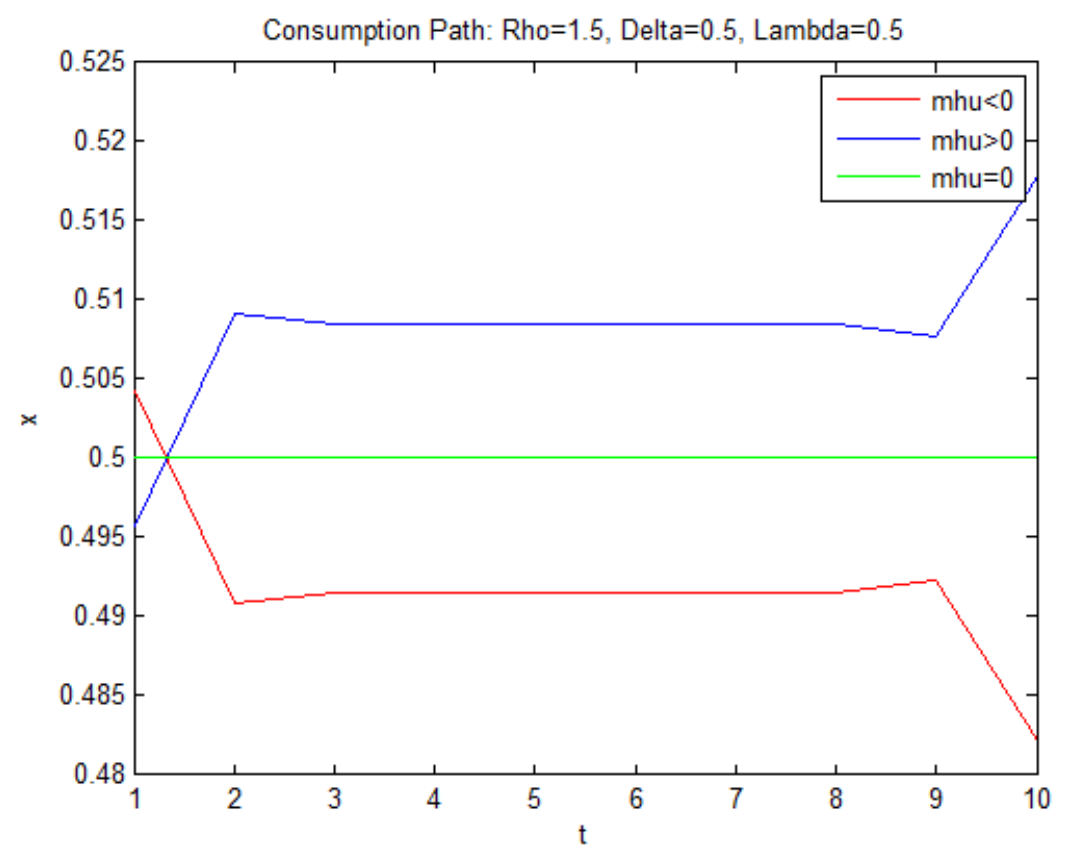

Fig. 4.2. Menu effects.

In the following figure we compare a myopic individual $(\delta=0)$ with a forward-looking individual $(\delta=1)$ who both have short emotional memories (i.e., except for the most recent ones, all previously produced emotions are forgotten) and a temptation shifted menu.

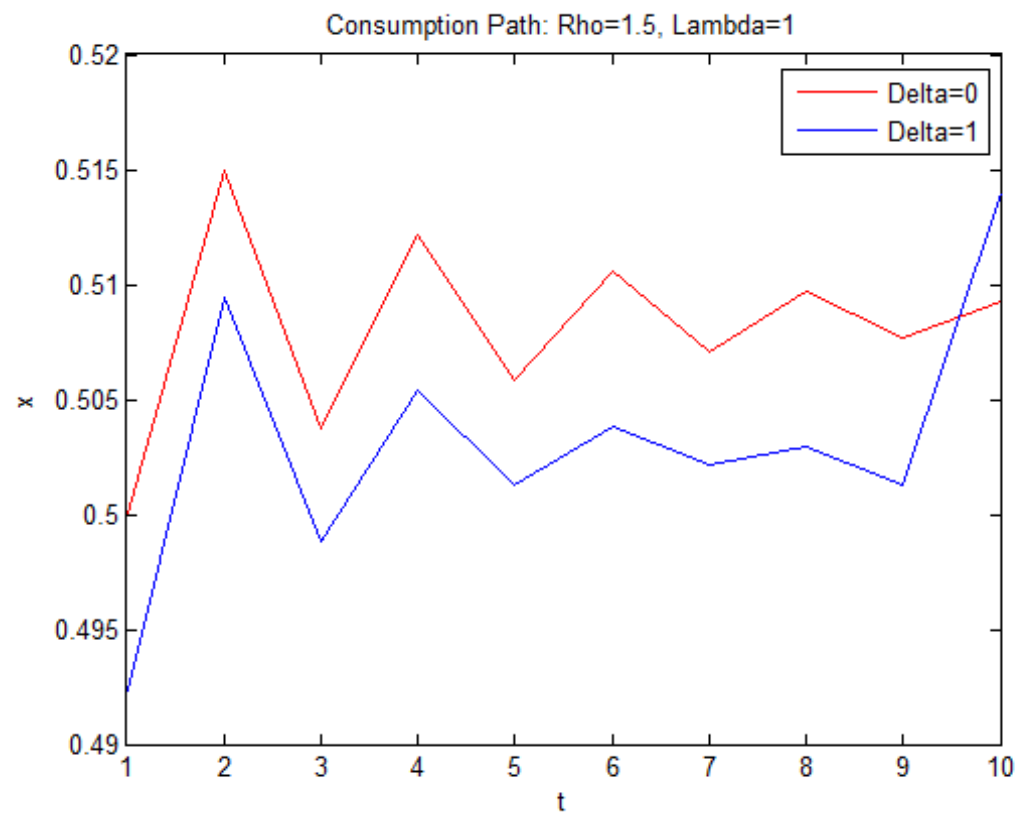

Fig. 4.3. Compensatory Feasting and Fasting Cycles. 
We observe that the consumption path above follows compensatory feasting and fasting cycles. In the last section we obtained these cycles for a myopic individual, while here we check whether they also hold for a forward-looking individual. Note that as in our two period model (Section 3.2) we find that compared with a myopic individual, a forwardlooking individual consumes less in the first period but more in the last period. The underlying strategy employed by the forward-looking individual here is one that manages his emotions by keeping consumption low (across all periods but the last) so as to minimize the costs that would otherwise prevent him from yielding to temptation in the last period. In other words, if the individual expects to yield to temptation (increasing $x$ ) tomorrow, he anticipates a high regret cost, $\gamma(x, g)$. Since the marginal cost of regret tomorrow increases with the regret (forgone restraint utility) created today, he tries to keep today's consumption closer to the restraint preference (decreasing $x$ ) in order to keep tomorrow's regret low. This makes yielding to temptation less costly tomorrow. Moreover as we proved in two period model (Proposition 1) the difference between consumption in the last and the first period increases with $\delta$, so in this sense, the more a consumer anticipates the future, the more he will show inconsistent consumption.

Finally, in Figure 4.3 we compare a myopic individual $(\delta=0)$ with a forward-looking individual $(\delta=1)$ who both have long emotional memories (i.e., all previously produced emotions are recalled) and a temptation shifted menu.

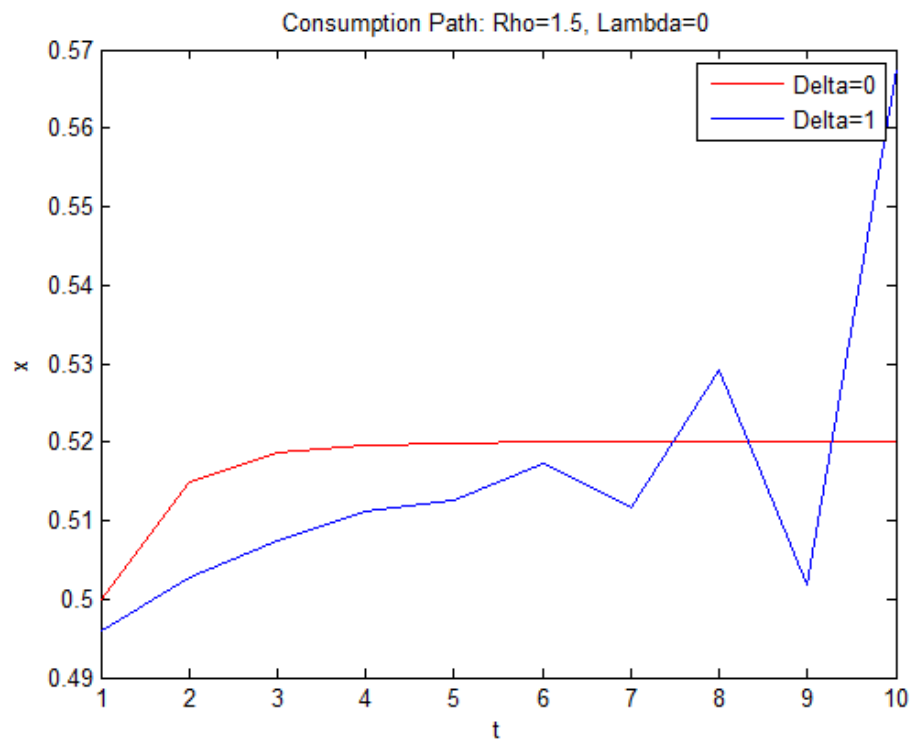

Fig. 3.3. Last period craving effect.

In this case the last period craving effect for the forward-looking individual is even 
more intense. If the menu is temptation shifted, the effort emotion is more important than the regret emotion, so $B_{T}$ will be high, and hence the last period consumption will be close to the temptation preference. As we have argued in Section 3.2, a forward-looking individual tries to minimize last period regret cost by decreasing consumption in $T-1$. Here we can see that this effect increases with $(1-\lambda)$ since the higher the emotional memory, the higher the weight of previous emotions on present decisions.

\section{Menu Uncertainty and Commitment}

In this section we relax the assumptions that the consumer has perfect information and no control over the alternatives on the menu. In particular we consider a three period, $t=\{0,1,2\}$, version of the model. In the first period $(t=0)$ the individual has to decide the set of available alternatives that he is going to face in the future. At the beginning of $t=1$ a set of uncontrolled alternatives arises, extending the previously chosen set of available alternatives. Then, consumption takes place in $t=1$ and $t=2$. We refer to the set of alternatives that the individual chooses in $t=0$ as the commitment menu $(M)$ to the uncontrolled alternatives as the menu extension $(Z)$, and to the menu faced in $t=1,2$ as the extended menu $(\bar{M}=M \cup Z)$. The menu extension is uncertain in $t=0$, and by simplicity we consider:

$$
Z=\left\{\begin{array}{cc}
1 & \text { with probability } \frac{p}{2}, \\
0 & \text { with probability } \frac{p}{2}, \\
\phi & \text { with probability }(1-p) .
\end{array}\right.
$$

Therefore, $p>0$ is the probability that new uncontrolled alternatives are created in $t=1$.

By the symmetry of the extension around $\frac{1}{2}$, it is immediate that there is no loss of generality in looking at symmetric commitment menus: $M=[1-m, m]$ with $m \in\left[\frac{1}{2}, 1\right]$.

We can interpret $M$ as food that a consumer has purchased for (committed) meals and $Z$ as (uncontrolled) special offers, free samples or invitations to eat alternative meals that the individual faces with probability $p$. The unexpected alternatives might be less-healthy high calorie products in line with the temptation preference $(Z=1)$ or more-healthy low calorie products in line with the restraint preference $(Z=0)$. 
Before explaining the optimal menu choice resulting from our emotional self-control representation, we consider the menu choice in a standard utility model and in a selfcontrol model with linear self-control costs (in the sense of Gul and Pesendorfer (2001)). Under a standard utility representation where emotions play no role $(\rho=0)$, the individual is indifferent to every menu containing $\underset{x \in M}{\arg \max } u(x)+v(x)=\frac{1}{2}$, the compromise between conflicting preferences. In other words, a broader menu can only be better for the individual (i.e., he has a preference for flexibility). Moreover, as we already mentioned in the literature review, a self-control representation with linear self-control costs implies a stationary consumption path given a menu. To see this, we consider an extension of Gul and Pesendorfer (2001) preferences, that also includes forgone restraint utility in the model, introduced by Kopylov (2012):

$$
W^{K}(M)=\max _{x \in M}[u(x)+v(x)]-\max _{x \in M} v(x)-k \max _{x \in M} u(x)
$$

where $k \in(0,1){ }^{8}$

Note that $x_{t}=\underset{x \in M}{\arg \max } u(x)+v(x)=\frac{1}{2}$ for any $M$ that includes the alternative $\frac{1}{2}$ (the compromise between the individual's conflicting preferences). Since $k>0$, any additional alternative $y \neq \frac{1}{2}$ creates negative consequences for the individual. If $y>\frac{1}{2}$, $\max _{x \in M} v(x)>v\left(\frac{1}{2}\right)$ when $Z \in\{\phi, 0\}$ while if $y<\frac{1}{2}, \max _{x \in M} u(x)>u\left(\frac{1}{2}\right)$ when $Z \in\{\phi, 1\}$, so the consumer's expected utility in $t=0$ decreases. In other words, by committing to the compromise between the conflicting preferences, the individual minimizes the negative consequences of the menu extensions and maximizes overall utility. Thus, the optimal menu will be $M^{F C}=\left\{\frac{1}{2}\right\}$ (i.e., a preference for commitment). Obviously, this result remains unchanged if we allow for uncontrolled alternatives. The consumer would be worse off with menu extension $Z$ but the preference for commitment prevails.

These above results are a consequence of stationary individual preferences. However, as we have seen with our emotional self-control representation, previous decisions can change the relative weight (cardinal scale) of conflicting preferences, creating a non-stationary consumption path in which an individual's preferences for commitment can be different.

\footnotetext{
${ }^{8}$ Kopylov (2012) axiomatizes these preferences for $k \in(-1,1)$. Here we only consider the case of costly forgone utilities, i.e., $k$ is positive, that it is consistent with our notion of regret. The representation also covers additional cases where $k$ is negative, thus not taken options that maximize restraint utility are valued by the consumer. This model offers explanations for perfectionist strivings (Stoeber and Otto (2006)) and seemingly irrational behavior that people exhibit when, for example, they pay for gym memberships or other products which they subsequently do not make use of (DellaVigna and Malmendier (2006)).
} 
In the following proposition we summarize some properties of the optimal commitment menu.

Proposition 2 The optimal commitment menu is $M^{*}=\left[1-m^{*}, m^{*}\right]$ where $m^{*}$ satisfies:

(i) $m^{*}>\frac{1}{2}$ if and only if $p>\bar{p}(\delta, \rho)$ and

(ii) If $m^{*}>\frac{1}{2}$, then $\frac{\partial m^{*}}{\delta p}>0, \frac{\partial m^{*}}{\delta \delta}>0$, and $\frac{\partial m^{*}}{\delta \rho}>0$.

The first property indicates that an individual with emotional self-control problems will want to commit to a menu with some (but not necessarily full) flexibility. This is an important novel result that offers new insights for the "preference for commitment" vs "preference for flexibility" debate. In our model, the uncontrolled novelties that extend menus contribute to the production of effort and regret emotions that, in turn, will change the relative power between conflicted preferences. A rational individual, that anticipates the emotional consequences of uncontrollable menu extensions, will demand some flexibility as he chooses his menu, so as to allow himself the ability to adapt his consumption accordingly. However, by choosing greater flexibility, additional costly emotions (regret and effort) are produced, so full flexibility $(m=1)$ could be suboptimal. ${ }^{9}$

The second property states some testable comparative statics. The menu flexibility increases with the probability of facing new uncontrolled alternatives $(p)$, the individual discount factor $(\delta)$, and the impact of emotions on consumer's preferences $(\rho)$.

\section{Conclusion}

We have developed a self-control model with menu-dependent emotions. In our model, effort and regret are emotional capitals produced by forgone temptation and restraint utilities recalled at a particular moment. We have proved several results in line with the empirical evidence that normal non-pathological humans demonstrate non-stationary

\footnotetext{
${ }^{9}$ Kopylov's (2012) representation also predicts a menu with some flexibility when $k<0$. However, the driving force is very different. In Kopylov (2012) the menu flexibility is the consequence of selfdeception, since additional options are never chosen by the individual, and hence the consumption path will be stationary. Whereas, in our model, acknowledgement of non-stationarity in preferences (due to emotional costs) implies a demand for a broader menu that allows one to resist or yield to temptation when uncontrolled menu extensions arise.
} 
consumption paths characterized by compensatory indulgence and restraint or feasting and fasting cycles. We have also explained why the amplitude of consumption cycles increases with individual's foresight and decreases with the recall of past self-control decisions (emotional memory). Moreover, we have shown that unavoidable (not necessarily chosen) alternatives can influence both an individual's consumption path and preferences for commitment.

There are several promising extensions of our basic model. First, our model only considers negative emotions, i.e., previous forgone utilities that impose a cost on the consumer's utility. However, we can easily imagine that the consumer may also experience positive emotions. For instance, when an individual resists temptation he typically feels effort (a negative emotion), but also feels pride (a positive emotion) as a consequence of his decision. The introduction of positive emotions will generate more complicated extended utilities that will complicate the analysis, but the main results of our paper should remain unchanged.

Our model assumes that the emotions are certain and produced in an individualistic vacuum. However, it may often be more realistic to assume that there is an element of uncertainty about additional negative and positive emotions that might be introduced as a consequence of new information or social preferences. For illustration, recall the example of the consumer who faces a special German Chocolate Cake option on his lunch menu and shows restraint by choosing not to consume the high-calorie cake. This foregone utility realized by this consumer's decision produces effort. Now let us consider that this consumer was dining with a couple partners who ordered the German Chocolate Cake. If the dining partners report that they find the seemingly tasty cake to be quite disgusting, the consumer may experience happiness and satisfaction (in addition to his previous effort) for not having ordered it. If on the other hand, the dining partners agree that the cake is the very best they have ever tasted and take pleasure in their shared experience, the consumer may experience additional forgone social utility (in addition to his previous individual effort) - not having opportunity to partake in the shared experience of this indulgence. In fact, food consumption has been shown to increase when meals are eaten in a social context, especially where there are positive moods (Schlundt \& Zimering, 1988) and friends or family (De Castro, 1994, 1995).

Our model proposes a new way to capture context and framing effects that can be tested in the laboratory. For example, consider a decisions faced by individuals with mutually exclusive goals and hence self-control problems. Typical examples of self-control 
problems include eating indulgently vs. dieting, engaging in work vs. leisure, cooperating vs. acting opportunistically, and spending vs. saving money. By manipulating the menu of available options faced by the individual (e.g. by exogenously introducing novel options whose appearance the decision maker has no control over) we can observe whether his behavior presents cycles of indulgence and restraint and whether the amplitude of these cycles depends on shifts of the menu as our model predicts.

Our model has also important implications for the study of pricing and marketing strategies. There are some papers that introduce temptation and self-control preferences when studying selling and pricing strategies employed by firms (e.g., Esteban et al. (2006), Eliaz and Spiegler (2006) and Gómez-Miñambres (2011)). These papers explore the implications of modeling consumers as having self-control representations, such as Gul and Pesendorfer (2001), that do not consider the menu dependence of self-control studied here. Therefore, they are not capable of explaining puzzling consumer's behaviors, such as why resisting purchase temptation today increases the probability to purchase a tempting product in the future (Dhar et al. (2007), Mukhopadhyay et al. (2008) and Mukhopadhyay and Johar (2009)). This behavior, commonly known in the marketing literature as the "shopping momentum effect", implies that an initial consumption decision can trigger additional consumption decisions that otherwise would not have been made. Our model with menu-dependent emotions provides a rationale of this effect: By resisting temptation today the consumer creates forgone temptation utility that increases the consumer's regret, making it more difficult to resist temptation in the future. Similarly, by yielding to temptation today the consumer is creating forgone restraint utility that increases the consumer's effort, making it easier to resist temptation in the future. Therefore, menu options offered by firms today will affect consumers' future demands by producing emotional experiences in consumers. This, of course, will have important implications for the strategies employed by firms (e.g. prices, sales and promotions, product locations) that deserves to be considered in future research. 


\section{References}

Baumeister, R. F., E. Bratslavsky, M. Muraven, and D. M. Tice. (1998). "Ego Depletion: Is the Active Self a Limited Resource?", Journal of Personality and Social Psychology, 74, 1252-1265.

Becker, G. S. (1996), "Accounting for Tastes", Cambridge, MA: Harvard University Press.

Becker, G. S. and K. M. Murphy. (1988), "A Theory of Rational Addiction", Journal of Political Economy, 96, 675-700.

Bernheim, B. D. and A. Rangel. (2004), "Addiction and Cue-Triggered Decision Processes", American Economic Review, 94, 1558-1590.

Brocas, I. and Carrilo, J.D. (2003), "The Psychology of Economic Decisions: Rationality and Well-Being", Oxford, UK: Oxford University Press.

Carrillo, J.D. (1998), "Self-Control, Moderate Consumption, and Craving", DEPR D.P. 2017, London.

Casper, R.C. and G. H. Beaton. (1992). "Food Deficits, Nutritional Status, and Appetite Signals", In Anderson, G. H. and S. H. Kennedy (Ed). The Biology of Feast and Famine: Relevance to Eating Disorders (pp.301-313). San Diego, CA: Academic Press.

De Castro, J. M. (1994). "Family and Friends Produce Greater Social Facilitation of Food Intake than other Companions", Physiology and Behavior, 56, 445-455.

De Castro J.M. (1995). "The Relationship of Cognitive Restraint to the Spontaneous Food and Fluid Intake of Freeliving Humans", Physiology and Behavior, 57, 287-95.

Dekel E., Lipman B.L., Rustichini A. (2009), "Temptation-Driven Preference", Review of Economic Studies 76, 937-971.

Dhar, R. J., Huber and U. Khan. (2007), "The Shooping Momentum Effect", Journal of Marketing Research, 44, 370-378.

Dockner, E. J. and G. Feichtinger. (1993), "Cyclical Consumption Patterns and Rational Addiction", American Economic Review, 83, 256-263.

Eliaz, K. and R. Spiegler. (2006), "Contracting with Diversely Naive Agents", Review of Economic Studies, 73, 689-714.

Esteban, S., Miyagawa, E. and M. Shum. (2006), "Nonlinear Pricing with Self-Control Preferences", Journal of Economic Theory, 135, 306-338.

Forster, J., Liberman, N. and E. T. Higgins. (2005), "Accessibility from Active and Fulfilled Goals", Journal of Experimental Social Psychology, 41, 220-239. 
Frank, R. H. (1988), "Passions within Reasons", W. W. Norton \& Company.

Fudenberg, D. and D. K. Levine. (2006), "A Dual-Self Model of Impulsive Control", American Economic Review, 96, 1449-1476.

Fudenberg, D. and D.K. Levine. (2010), "Timing and Self-Control", Econometrica, $80,1-42$.

Gómez-Miñambres, J. (2011), "Temptation, Horizontal Differentiation and Monopoly Pricing", Working Paper 11-24 Departamento de Economia, Universidad Carlos III de Madrid.

Gul, F. and W. Pesendorfer. (2001), "Temptation and Self-control", Econometrica, 69, 1403-1436.

Gul, F. and W. Pesendorfer. (2007), "Harmful Addiction", Econometrica, 74, 147-172.

Hare, T. A., C. F. Camerer and A. Rangel. (2009), "Self-Control in Decision Making Involves Modulation of the vmPFC Valuation System", Science, 324, 646-648.

Heatherton, T. F., P. Nichols, F. and P. Keel. (1995), "Body Weight, Dieting, and Eating Disorder Symptoms Among College Students, 1982 to 1992", The American Journal of Psychiatry, 152, 1623-1631.

Hotelling, H. (1929), "Stability in Competition", Economic Journal, 39, 41-57.

Iannaccone, L. (1986), "Addiction and Satiation", Economics Letters, 21, 95-99.

Job, V., Dweck, C. S. and G. M. Walton. (2010). "Ego Depletion-Is It All in Your Head?: Implicit Theories About Willpower Affect Self-Regulation". Psychological Science, 21, 1686-1693.

Kopylov, I. (2012), "Perfectionism and Choice", Econometrica (forthcoming).

Kurth, C. L., D. D. Krahn, K. Nairn and A. Drewnowski .(1995), "The Severity of Dieting and Bingeing Behaviors in College Women: Interview Validation of Survey Data", Journal of Psychiatric Research, 29, 211-225.

Kurzban, R. (2010). "Does the Brain Consume Additional Glucose During SelfControl Tasks?" Evolutionary Psychology, 8, 244-259.

Laibson, D. (2001), "A Cue-Theory of Consumption", Quarterly Journal of Economics, 116, 81-120.

Livnat A. and N. Pippenger. (2006), "An Optimal Brain Can Be Composed of Conflicting Agents", PNAS, 103, 3198-3202.

Logue, A.W. (1988), "Research on self-control: An integrating framework", Behavioral and Brain Sciences, 114, 665-709

Lynch, W. C., A. Everingham, J. Dubitzky, M. Hartman and T. Kasser. (200), "Does 
binge eating play a role in the self-regulation of moods?" Integrative Physiological and Behavioral Science, 35, 298-313.

McClure, S. M., D. Laibson, G. Loewenstein and J. D. Cohen (2004), "Separate Neural Systems Value Immediate and Delayed Monetary Rewards", Science, 306, 503-507.

Mertz, W. and J. L. Kelsay. (1984). Rationale and Design of the Beltsville One-Year Dietary Intake Study. American Journal of Clinical Nutrition. 40 (Suppl.), 13-23.

Mukhopadhyay, A., J. Sengupta and S. Ramanathan. (2008), "Recalling Past Temptations: An Information-Processing Perspective on the Dynamics of Self-Control", Journal of Consumer Research, 35, 586-599.

Mukhopadhyay, A., J. and G. V. Johar. (2009), "Indulgence as Self-Reward for Prior Shopping Restraint: A Justification-Based Mechanism", Journal of Consumer Psychology, 19, 334-345.

Noor, J. and N. Takeoka. (2010), "Menu-Dependent Self-Control", Boston University Working Paper.

Pinker, S (1997), "How the Mind Works", New York: Norton.

Rachlin, H. (1995), "Self-Control: Beyond Commitment", Behavioral and Brain Sciences, 18, 109-159.

Sarver, T. (2008), "Anticipating Regret: Why Fewer Options May Be Better", Econometrica, 76, 263-305.

Schlundt, D. G. \& Zimering, R. T. (1988). "The Dieter's Inventory of Eating Temptations: A Measure of Weight Control Competence", Addictive Behaviors, 13, 151-164.

Stigler, G.J. and G.S. Becker. (1977), "De Gustibus Non Est Disputandum", American Economic Review, 67, 76-90.

Stoeber, J. and K. Otto. (2006), "Positive Conceptions of Perfectionism: Approaches, Evidence, Challenges", Personality and Social Psychology Review, 10, 295-319.

Strotz, R. H. (1955), "Myopia and Inconsistency in Dynamic Utility Maximization", The Review of Economic Studies, 23, 165-180.

Tooby, J., Cosmides, L., Sell, A., Lieberman, D., and D. Sznycer. (2008), "Internal Regulatory Variables and the Design of Human Motivation: A Computational and Evolutionary Approach", In A. J. Elliot (Ed.), Handbook of approach and avoidance motivation (pp. 251-271). Mahwah, NJ: Lawrence Erlbaum Associates.

Tooby, J., and L. Cosmides. (1992), "The Psychological Foundations of Culture", In J. H. Barkow, L. Cosmides, \& J. Tooby (Eds.), The adapted mind: Evolutionary psychology and the generation of culture (pp. 19 -36). Oxford, England: Oxford University Press. 
Tversky, A. and E. Shafir. (1992), "Choice Under Conflict: The Dynamics of Deferred Decision", Psychological Science 3, 358-361.

Whitesidea, U., E. Chenb, C. Neighborsb, D. Huntera, T. Loa and M. Larimerb (2007), "Difficulties Regulating Emotions: Do Binge Eaters Have Fewer Strategies to Modulate and Tolerate Negative Affect?", Eating Behaviors, 8, 162-169. 


\section{APPENDIX}

\section{Proof of Lemma 1}

By the emotional balance transition equation and the fact that $x_{t}=\frac{1}{2}+\frac{\rho}{4} B_{t}$ we know that

$$
B_{t+1}=\left(1-\lambda-\frac{\rho}{2}\right) B_{t}+\mu .
$$

Solving recursively, with the initial condition $B_{1}=0$, we get

$$
B_{t}=2 \mu \frac{1-\left[1-\lambda-\frac{\rho}{2}\right]^{t-1}}{2 \lambda+\rho} .
$$

\section{Proof of Corollary 1}

Immediate from Lemma 1. Q.E.D

\section{Proof of Corollary 2}

Immediate from Lemma 1. Q.E.D

\section{Proof of Proposition 1}

Immediate from equations (2) and (3). Q.E.D

\section{Proof of Proposition 2}

Using equations (2) and (3) we know that the individual consumption given the commitment menu chosen in $t=0$ is given by.

$$
\begin{aligned}
& x_{1}(\bar{M})=\frac{1}{2}-\frac{\delta \rho^{2}}{8+4 \delta \rho\left(1-\frac{\rho}{2}\right)} \mu(\bar{M}), \\
& x_{2}(\bar{M})=\frac{1}{2}+\frac{\rho(2+\delta \rho)}{8+4 \delta \rho\left(1-\frac{\rho}{2}\right)} \mu(\bar{M}) .
\end{aligned}
$$

with $\mu(M \cup\{1\})=(1-m)^{2}, \mu(M \cup\{0\})=-(1-m)^{2}$ and $\mu(M)=0$.

Using $x_{1}(\bar{M})$ and $x_{2}(\bar{M})$ we get $W_{2}(\bar{M})=U\left(x_{2}(\bar{M}), e_{2}\left(x_{1}(\bar{M})\right)\right)+V\left(x_{2}(\bar{M}), g_{2}\left(x_{1}(\bar{M})\right)\right)$ and $W_{1}(\bar{M})=U\left(x_{1}(\bar{M}), 0\right)+V\left(x_{1}(\bar{M}), 0\right)+\delta W_{2}(\bar{M})$. 
The menu that maximizes the individual's ex-ante surplus in $t=0$ is given by the solution of the following problem:

$$
m^{*} \in \underset{m \in\left[\frac{1}{2}, 1\right]}{\arg \max } \frac{p}{2} W_{1}(M \cup\{1\})+\frac{p}{2} W_{1}(M \cup\{0\})+(1-p) W_{1}(M)
$$

Whose solution is:

$$
m^{*}=1-\frac{|4+\delta \rho(2-\rho)|}{\sqrt{p \rho\left(8+\delta \rho\left(8+2 \rho(1+\delta)+3 \delta \rho^{2}\right)\right)}} .
$$

Therefore,

$$
m^{*}>\frac{1}{2} \text { iff } p>\bar{p}(\delta, \rho)
$$

with

$$
\bar{p}(\delta, \rho)=\frac{4(4+\delta \rho(2-\rho))^{2}}{\rho\left(8+\delta \rho\left(8+2 \rho(1+\delta)+3 \delta \rho^{2}\right)\right)} .
$$

\section{COMPUTATION OF THE OPTIMAL CONSUMPTION PATH}

We know that consumption in the last period is given by $x_{T}=\frac{1}{2}+\frac{\rho}{4} B_{T}$. Where $B_{T}$ is the consequence of previous self-control decisions. Moving backwards and solving $\max _{x \in M} U\left(x, e_{t}\right)+V\left(x, g_{t}\right)+\delta W_{t+1}$ recursively we get the following result summarized in Lemma 2.

Lemma 2 Let's consider $\rho \in[0,2]$. Solving the problem recursively we get that for all $t<T$ :

$$
\begin{aligned}
x_{1} & =\beta_{1} x_{2}+\gamma_{1}, \\
x_{t} & =\alpha_{t}\left[x_{t-1}+(1-\lambda) x_{t-2}+\ldots+(1-\lambda)^{t-2} x_{1}\right]+\beta_{t} x_{t+1}+\gamma_{t} \text { for all } t \in\{2, \ldots, T-2\} \text { and } \\
x_{T-1} & =\alpha_{T-1}\left[x_{T-2}+(1-\lambda) x_{T-3}+\ldots+(1-\lambda)^{T-3} x_{1}\right]+\gamma_{T-1} .
\end{aligned}
$$

Where $\alpha_{t}, \beta_{t}$ and $\gamma_{t}$ are recursive functions defined in the Appendix.

\section{Proof}

Consumption in period $T$ is given by $x_{T}=\underset{x \in M}{\arg \max } W_{T}=\frac{1}{2}+\frac{\rho}{4} B_{T}$. The first order condition (FOC) of the maximization problem in period $t<T$ is given by

$$
\frac{d W_{t}}{d x_{t}}=-4 x_{t}+2+\rho B_{t}+\delta \frac{d W_{t+1}}{d x_{t}}=0
$$


Plugging $x_{T}$ in $W_{T-1}$ and taking derivatives we get:

$$
\frac{d W_{T}}{d x_{T-1}}=-\rho\left[\frac{\rho}{2}\left[(1-\lambda) B_{T-1}+\mu\right]-\left(1-2 x_{T-1}\right)\left(1-\frac{\rho}{2}\right)\right] .
$$

Solving the FOC (4) in period $T-1$ we obtain:

$$
x_{T-1}=\frac{1}{2}+\frac{\rho\left(B_{t}\left(1-(1-\lambda) \frac{\delta \rho}{2}\right)-\frac{\delta \rho}{2} \mu\right)}{4+2 \delta \rho\left(1-\frac{\rho}{2}\right)} .
$$

If we keep moving backwards we get that for all $t<T$

$$
x_{t}=\frac{1}{2}+\frac{\rho\left(B_{t}\left(1-(1-\lambda) \frac{\delta \rho}{2} f_{t}\right)-\frac{\delta \rho}{2} \mu f_{t}-\delta\left(1-f_{t}\right)\left(1-2 x_{t+1}\right)\right)}{4+2 \delta \rho\left(1-\frac{\rho}{2} f_{t}\right)} .
$$

where $f_{T-1}=1$ and $f_{t}=\frac{1-(1-\lambda) \frac{\delta \rho}{2} f_{t+1}}{1+\frac{\delta \rho}{2}\left(1-\frac{\rho}{2} f_{t+1}\right)}$ for all $t<T-1$.

Given the initial emotional balance, $B_{1}$, we can write emotional balance in period $t>2$ as a function of previous consumption decisions:

$$
B_{t}=(1+\mu)\left[\frac{1-(1-\lambda)^{t-1}}{\lambda}\right]-2\left[x_{t-1}+(1-\lambda) x_{t-2}+\ldots+(1-\lambda)^{t-2} x_{1}\right] .
$$

Therefore, we can rewrite (5) as:

$x_{1}=\beta_{1} x_{2}+\gamma_{1}$ and

$x_{t}=\alpha_{t}\left[x_{t-1}+(1-\lambda) x_{t-2}+\ldots+(1-\lambda)^{t-2} x_{1}\right]+\beta_{t} x_{t+1}+\gamma_{t}$ for all $t \in\{2, \ldots, T-1\}$.

where $\alpha_{t}=-\frac{\rho\left(1-(1-\lambda) \frac{\delta \rho}{2} f_{t}\right)}{2+\delta \rho\left(1-\frac{\rho}{2} f_{t}\right)}, \beta_{t}=-\frac{\delta \rho\left(1-f_{t}\right)}{2+\delta \rho\left(1-\frac{\rho}{2} f_{t}\right)}$ and

$$
\gamma_{t}=\frac{1}{2}-\frac{\delta \rho\left(\frac{\rho}{2} \mu f_{t}-\left(1-f_{t}\right)\right)}{4+2 \delta \rho\left(1-\frac{\rho}{2} f_{t}\right)}-\frac{\alpha_{t}}{2}(1+\mu)\left[\frac{1-(1-\lambda)^{t-1}}{\lambda}\right] .
$$

The second order condition (SOC) of the maximization problem in period $t<T$ is given by

$$
\frac{d^{2} W_{t}}{d^{2} x_{t}}=-4-2 \delta \rho\left[1-\frac{\rho}{2} \frac{1-(1-\lambda) \frac{\delta \rho}{2} f_{t}}{1+\frac{\delta \rho}{2}\left(1-\frac{\delta \rho}{2}\left(1-\frac{\rho}{2} f_{t}\right)\right)}\right]<0
$$

Therefore, a sufficient condition for SOC to be satisfied is $\rho \in[0,2]$.

Q.E.D

The function contained in Lemma 2 is not a solution in itself but a relation between optimal decisions in different periods: Today's action $\left(x_{t}\right)$ is a linear function of past decisions $\left(x_{1}, \ldots, x_{t-1}\right)$ and tomorrow's action $\left(x_{t+1}\right)$. It implies that, consumption in two 
adjacent periods are substitutes. Hence an increase in the current consumption decrease the individual future consumption.

In order to get the solution, note that we can plug $x_{1}\left(x_{2}\right)$ in $x_{2}\left(x_{1}, x_{3}\right)$ and solve the resulting equation to get $x_{2}\left(x_{3}\right)$. If we keep doing this we get $x_{t}$ as a function only of $x_{t+1}$ :

$$
x_{t}=\frac{k_{t}+\gamma_{t}+\beta_{t} x_{t+1}}{1-\alpha_{t} \beta_{t-1} h_{t}} \text { for all } t \in\{2, \ldots, T-2\}
$$

where $h_{t}=\frac{1+\beta_{t-2}(1-\lambda) h_{t-1}}{1-\alpha_{t-1} \beta_{t-2} h_{t-1}}$ and $k_{t}=\alpha_{t}\left(h_{t}\left(k_{t-1}+\gamma_{t-1}\right)+(1-\lambda) \frac{k_{t-1}}{\alpha_{t-1}}\right)$.

Now we can use $x_{T-1}=\frac{k_{T-1}+\gamma_{T-1}}{1-\alpha_{T-1} \beta_{T-2} h_{T-2}}$, which is a known scalar, and find the optimal decision path following the transition equation (6). 


\section{2}

\section{Economic Science Institute Working Papers}

12-19 Schniter, E., Sheremeta, R., and Sznycer, D. Building and Rebuilding Trust with Promises and Apologies.

12-18 Shields, T. and Xin, B. Higher-order Beliefs in Simple Trading Models.

12-17 Pfeiffer, G. and Shields, T. Performance-Based Compensation and Firm Value: Experimental evidence.

12-16 Kimbrough, E. and Sheremeta, R. Why Can't We Be Friends? Entitlements, bargaining, and conflict.

12-15 Mago, S., Savikhin, A., and Sheremeta, R. Facing Your Opponents: Social identification and information feedback in contests.

12-14 McCarter, M., Kopelman, S., Turk, T. and Ybarra, C. Too Many Cooks Spoil the Broth: How the tragedy of the anticommons emerges in organizations.

12-13 Chowdhury, S., Sheremeta, R. and Turocy, T. Overdissipation and Convergence in Rent-seeking Experiments: Cost structure and prize allocation rules.

12-12 Bodsky, R., Donato, D., James, K. and Porter, D. Experimental Evidence on the Properties of the California's Cap and Trade Price Containment Reserve.

12-11 Branas-Garza, P., Espin, A. and Exadaktylos, F. Students, Volunteers and Subjects: Experiments on social preferences.

12-10 Klose, B. and Kovenock, D. Extremism Drives Out Moderation.

12-09 Buchanan, J. and Wilson, B. An Experiment on Protecting Intellectual Property.

12-08 Buchanan, J., Gjerstad, S. and Porter, D. Information Effects in Multi-Unit Dutch Auctions.

12-07 Price, C. and Sheremeta, R. Endowment Origin, Demographic Effects and Individual Preferences in Contests.

12-06 Magoa, S. and Sheremeta, R. Multi-Battle Contests: An experimental study.

12-05 Sheremeta, R. and Shields, T. Do Liars Believe? Beliefs and Other-Regarding Preferences in Sender-Receiver Games.

12-04 Sheremeta, R., Masters, W. and Cason. T. Winner-Take-All and Proportional-Prize Contests: Theory and experimental results.

12-03 Buchanan, J., Gjerstad, S. and Smith, V. There's No Place Like Home. 
12-02 Corgnet, B. and Rodriguez-Lara, I. Are you a Good Employee or Simply a Good Guy? Influence Costs and Contract Design.

12-01 Kimbrough, E. and Sheremeta, R. Side-Payments and the Costs of Conflict.

\section{1}

11-20 Cason, T., Savikhin, A. and Sheremeta, R. Behavioral Spillovers in Coordination Games.

11-19 Munro, D. and Rassenti, S. Combinatorial Clock Auctions: Price direction and performance.

11-18 Schniter, E., Sheremeta, R., and Sznycer, D. Restoring Damaged Trust with Promises, Atonement and Apology.

11-17 Brañas-Garza, P., and Proestakis, A. Self-discrimination: A field experiment on obesity.

11-16 Brañas-Garza, P., Bucheli, M., Paz Espinosa, M., and García-Muñoz, T. Moral Cleansing and Moral Licenses: Experimental evidence.

11-15 Caginalp, G., Porter, D., and Hao, L. Asset Market Reactions to News: An experimental study.

11-14 Benito, J., Branas-Garz, P., Penelope Hernandez, P., and Sanchis Llopis, J. Strategic Behavior in Schelling Dynamics: A new result and experimental evidence.

11-13 Chui, M., Porter, D., Rassenti, S. and Smith, V. The Effect of Bidding Information in Ascending Auctions.

11-12 Schniter, E., Sheremeta, R. and Shields, T. Conflicted Minds: Recalibrational emotions following trust-based interaction.

11-11 Pedro Rey-Biel, P., Sheremeta, R. and Uler, N. (Bad) Luck or (Lack of) Effort?: Comparing social sharing norms between US and Europe.

11-10 Deck, C., Porter, D., and Smith, V. Double Bubbles in Assets Markets with Multiple Generations.

11-09 Kimbrough, E., Sheremeta, R., and Shields, T. Resolving Conflicts by a Random Device.

11-08 Brañas-Garza, P., García-Muñoz, T., and Hernan, R. Cognitive effort in the Beauty Contest Game.

11-07 Grether, D., Porter, D., and Shum, M. Intimidation or Impatience? Jump Bidding in On-line Ascending Automobile Auctions.

11-06 Rietz, T., Schniter, E., Sheremeta, R., and Shields, T. Trust, Reciprocity and Rules.

11-05 Corgnet, B., Hernan-Gonzalez, R., and Rassenti, S. Real Effort, Real Leisure and Real-time Supervision: Incentives and peer pressure in virtual organizations. 
11-04 Corgnet, B. and Hernán-González R. Don’t Ask Me If You Will Not Listen: The dilemma of participative decision making.

11-03 Rietz, T., Sheremeta, R., Shields, T., and Smith, V. Transparency, Efficiency and the Distribution of Economic Welfare in Pass-Through Investment Trust Games.

11-02 Corgnet, B., Kujal, P. and Porter, D. The Effect of Reliability, Content and Timing of Public Announcements on Asset Trading Behavior.

11-01 Corgnet, B., Kujal, P. and Porter, D. Reaction to Public Information in Markets: How much does ambiguity matter?

\section{0}

10-23 Sheremeta, R. Perfect-Substitutes, Best-Shot, and Weakest-Link Contests between Groups.

10-22 Mago, S., Sheremeta, R., and Yates, A. Best-of-Three Contests: Experimental evidence.

10-21 Kimbrough, E. and Sheremeta, R. Make Him an Offer He Can't Refuse: Avoiding conflicts through side payments.

10-20 Savikhim, A. and Sheremeta, R. Visibility of Contributions and Cost of Inflation: An experiment on public goods.

10-19 Sheremeta, R. and Shields, T. Do Investors Trust or Simply Gamble?

10-18 Deck, C. and Sheremeta, R. Fight or Flight? Defending Against Sequential Attacks in the Game of Siege.

10-17 Deck, C., Lin, S. and Porter, D. Affecting Policy by Manipulating Prediction Markets: Experimental evidence.

10-16 Deck, C. and Kimbrough, E. Can Markets Save Lives? An Experimental Investigation of a Market for Organ Donations.

10-15 Deck, C., Lee, J. and Reyes, J. Personality and the Consistency of Risk Taking Behavior: Experimental evidence.

10-14 Deck, C. and Nikiforakis, N. Perfect and Imperfect Real-Time Monitoring in a Minimum-Effort Game.

10-13 Deck, C. and Gu, J. Price Increasing Competition? Experimental Evidence.

10-12 Kovenock, D., Roberson, B., and Sheremeta, R. The Attack and Defense of Weakest-Link Networks.

10-11 Wilson, B., Jaworski, T., Schurter, K. and Smyth, A. An Experimental Economic History of Whalers' Rules of Capture. 
10-10 DeScioli, P. and Wilson, B. Mine and Thine: The territorial foundations of human property.

10-09 Cason, T., Masters, W. and Sheremeta, R. Entry into Winner-Take-All and Proportional-Prize Contests: An experimental study.

10-08 Savikhin, A. and Sheremeta, R. Simultaneous Decision-Making in Competitive and Cooperative Environments.

10-07 Chowdhury, S. and Sheremeta, R. A generalized Tullock contest.

10-06 Chowdhury, S. and Sheremeta, R. The Equivalence of Contests.

10-05 Shields, T. Do Analysts Tell the Truth? Do Shareholders Listen? An Experimental Study of Analysts' Forecasts and Shareholder Reaction.

10-04 Lin, S. and Rassenti, S. Are Under- and Over-reaction the Same Matter? A Price Inertia based Account.

10-03 Lin, S. Gradual Information Diffusion and Asset Price Momentum.

10-02 Gjerstad, S. and Smith, V. Household Expenditure Cycles and Economic Cycles, 1920-2010.

10-01 Dickhaut, J., Lin, S., Porter, D. and Smith, V. Durability, Re-trading and Market Performance.

\section{9}

09-11 Hazlett, T., Porter, D., and Smith, V. Radio Spectrum and the Disruptive Clarity OF Ronald Coase.

09-10 Sheremeta, R. Expenditures and Information Disclosure in Two-Stage Political Contests.

09-09 Sheremeta, R. and Zhang, J. Can Groups Solve the Problem of Over-Bidding in Contests?

09-08 Sheremeta, R. and Zhang, J. Multi-Level Trust Game with "Insider" Communication.

09-07 Price, C. and Sheremeta, R. Endowment Effects in Contests.

09-06 Cason, T., Savikhin, A. and Sheremeta, R. Cooperation Spillovers in Coordination Games.

09-05 Sheremeta, R. Contest Design: An experimental investigation.

09-04 Sheremeta, R. Experimental Comparison of Multi-Stage and One-Stage Contests.

09-03 Smith, A., Skarbek, D., and Wilson, B. Anarchy, Groups, and Conflict: An experiment on the emergence of protective associations.

09-02 Jaworski, T. and Wilson, B. Go West Young Man: Self-selection and endogenous property rights.

09-01 Gjerstad, S. Housing Market Price Tier Movements in an Expansion and Collapse. 


\section{8}

08-09 Dickhaut, J., Houser, D., Aimone, J., Tila, D. and Johnson, C. High Stakes Behavior with Low Payoffs: Inducing preferences with Holt-Laury gambles.

08-08 Stecher, J., Shields, T. and Dickhaut, J. Generating Ambiguity in the Laboratory.

08-07 Stecher, J., Lunawat, R., Pronin, K. and Dickhaut, J. Decision Making and Trade without Probabilities.

08-06 Dickhaut, J., Lungu, O., Smith, V., Xin, B. and Rustichini, A. A Neuronal Mechanism of Choice.

08-05 Anctil, R., Dickhaut, J., Johnson, K., and Kanodia, C. Does Information Transparency Decrease Coordination Failure?

08-04 Tila, D. and Porter, D. Group Prediction in Information Markets With and Without Trading Information and Price Manipulation Incentives.

08-03 Thomas, C. and Wilson, B. Horizontal Product Differentiation in Auctions and Multilateral Negotiations.

08-02 Oprea, R., Wilson, B. and Zillante, A. War of Attrition: Evidence from a laboratory experiment on market exit.

08-01 Oprea, R., Porter, D., Hibbert, C., Hanson, R. and Tila, D. Can Manipulators Mislead Prediction Market Observers? 